\section{Light Intensity Affects Gibberellic Acid Content in Kentucky Bluegrass}

\author{
Z.G. Tan and Y.L. Qian ${ }^{1}$ \\ Dept. of Horticulture and Landscape Architecture, Colorado State Univ., \\ Fort Collins, CO 80523-1173
}

Additional index words. Poa pratensis, shade, trinexapac-ethyl

\begin{abstract}
Turfgrasses grown under low light conditions generally exhibit increased shoot elongation. Gibberellic acids (GAs), $\mathbf{G A}_{1}$ in particular, promote stem elongation in grass species. $\mathrm{GA}_{20}$ is the immediate precursor of $\mathbf{G A}_{1}$. However, a direct quantitative measurement of $\mathrm{GA}_{1}$ and $\mathrm{GA}_{20}$ has not been reported for turfgrass under different light intensities. This study was conducted in a greenhouse to quantify the endogenous levels of $\mathbf{G A}_{1}$ and $\mathbf{G A}_{20}$ of 'KenblueTimes', 'Livingston', and 'NuGlade' Kentucky bluegrass (Poa pratensis $\mathrm{L}$.) under two light intensities with and without trinexapacethyl (TE) application. $\mathrm{GA}_{1}$ and $\mathrm{GA}_{20}$ content in leaf tissue were analyzed using gas chromatography-mass spectrometry with deuterium-labeled $\mathrm{GA}_{1}$ and $\mathrm{GA}_{20}$ as internal standards. Light reduction of $73 \%$ under greenhouse conditions increased $\mathrm{GA}_{1}$ by $44 \%$ to $47 \%$ and $\mathbf{G A}_{20}$ by $16 \%$ to $50 \%$. 'NuGlade' had a $\mathbf{G A}_{1}$ content $20 \%$ lower than that of 'Kenblue', suggesting that the dwarf characteristics of 'NuGlade' may be related to its low GA content. The application of TE $\left(0.1 \mathrm{~kg}^{\prime} \mathrm{ha}^{-1}\right)$ reduced GA concentration by $47 \%$, but increased $\mathrm{GA}_{20}$ concentration by $146 \%$, supporting the contention that $\mathrm{TE}$ inhibited $\mathrm{GA}_{1}$ biosynthesis by blocking the conversion of $\mathrm{GA}_{20}$ to $\mathrm{GA}_{1}$. Chemical names used: 4-(cyclopropyl--hydroxy-methylene)-3,5-dioxo-cyclohexanecarboxylic acid ethyl ester (trinexapac-ethyl); gibberellic acid (GA).
\end{abstract}

Gibberellins are a group of tetracyclic diterpenoids that are involved in various plant growth and development processes, such as stem growth, flower and seed development, and seed germination (Graebe, 1987). The involvement of gibberellic acid (GA) in regulating shoot elongation in higher plants is particularly interesting to the management of turfgrass. Gibberellic acids, $\mathrm{GA}_{1}, \mathrm{GA}_{19}, \mathrm{GA}_{20}$, $\mathrm{GA}_{44}$, and $\mathrm{GA}_{53}$, have been identified from Kentucky bluegrass [Poa pratensis L. (KBG)], the most widely used cool-season turfgrass (Junttila et al., 1997). Junttila et al. (1997) found that long-day photoperiods stimulate gibberellic acid synthesis in $\mathrm{KBG}$, and as a consequence, stimulate increased leaf elongation. Heide et al. (1985) suggested that $\mathrm{GA}_{1}, \mathrm{GA}_{3}$, and $\mathrm{GA}_{4}$ cause shoot and leaf growth of Kentucky bluegrass. However, in grass species, $\mathrm{GA}_{1}$ is primarily responsible for shoot and leaf elongation. $\mathrm{GA}_{20}$ is the immediate precursor of $\mathrm{GA}_{1}$ (Reid and Ross, 1991).

Much research about the influence of light and endogenous GAs on KBG shoot elongation has focused on photoperiod (Junttila et al., 1997; Heide et al., 1985). The effects of light intensity on shoot elongation and GAs levels are poorly understood. When KBG is grown under low light intensity, it first exhibits increased shoot and leaf elongation (Beard, 1965). Enhanced shoot elongation is a shade avoidance mechanism of plants. This is rather undesirable in turfgrass since the goal for turfgrass management

Received for publication 20 Sept. 2001.Accepted for publication 2 May 2002.Funding was provided in part by the Rocky Mountain Turfgrass Research Foundation and Colorado Agricultural Experimental Station (Project 780).

${ }^{1}$ To whom reprint requests should be addressed. E-mail address: yaqian@lamar.colostate.edu. is to produce a dense grass sward with reduced upright growth. Rapid shoot elongation results in more shoot removal during regular mowing and accelerates energy depletion, which may result in reduced rooting and tillering, and a decline in overall turf quality (Qian et al., 1998). The increased shoot elongation in KBG under shade may, in part, result from increased GA content, increased sensitivity of the plant to GAs, or both. However, no research has been done to quantify the effect of light intensity on endogenous $\mathrm{GA}_{1}$ and $\mathrm{GA}_{20}$ content for turfgrass. This information is essential in understanding the physiological response to low irradiance conditions and facilitate wise use of GAand GA reducing compounds for the regulation of shoot elongation in turfgrass.

Trinexapac-ethyl (TE) is an anti-gibberellic acid type of plant growth regulator, which inhibits shoot elongation by blocking the conversion of $\mathrm{GA}_{20}$ to $\mathrm{GA}_{1}$, the last step of GA biosynthesis involving 3B-hydroxylation of $\mathrm{GA}_{20}$ (Adams et al., 1992). Research shows that TE restricts shoot elongation and improves Zoysiagrass and KBG quality under low light conditions (Qian and Engelke, 1999; Qian et al., 1998; Ervin et al., 1999; and Stier and Rogers, 2001).

The objectives of this study were: 1) to quantify the endogenous $\mathrm{GA}_{1}$ and $\mathrm{GA}_{20}$ content of three KBG cultivars under two light intensities, and 2) to determine the influence of TE on $\mathrm{GA}_{1}$ and $\mathrm{GA}_{20}$ content of $\mathrm{KBG}$ under low light intensity.

\section{Materials and Methods}

Plant materials. The experiments were conducted in a fiberglass-reinforced plastic greenhouse from Nov. 1999 to Jul. 2000. Average air temperature in the greenhouse was $\approx 20$
${ }^{\circ} \mathrm{C}$ at $0800 \mathrm{Hr}, 24^{\circ} \mathrm{C}$ at $1400 \mathrm{HR}$, and $18{ }^{\circ} \mathrm{C}$ at $0200 \mathrm{HR}$. Three cultivars of KBG were selected for the experiment based on their morphological characteristics: 'NuGlade' KBG exhibits dwarf, compact shoot growth; 'Livingston' KBG produces medium shoot growth; and 'Kenblue' KBG has a fast shoot growth rate and leaf elongation. Sod pieces $30 \mathrm{~cm}$ in diam. were excised from field plots. They were handwashed to remove soil, and planted in a total of 48 plastic containers $(30 \mathrm{~cm}$ in diameter and $40 \mathrm{~cm}$ deep). The containers were filled with a mix of 85 sand :15 compost (by volume). Initially, plants were grown under natural light in the greenhouse, with photosynthetically active radiation ranged from $\approx 150 \mu \mathrm{mol} \cdot \mathrm{m}^{-2} \cdot \mathrm{s}^{-1}$ on cloudy days to $1150 \mu \mathrm{mol} \cdot \mathrm{m}^{-2} \cdot \mathrm{s}^{-1}$ on sunny days. Turf was clipped weekly at a 3.5-cm height and clippings were removed. This experiment was conducted as a three-way factorial design with four replications. The three treatment factors were cultivar, shade, and TE.

Five months after soding, light treatments were randomly applied to the 48 containers. The light treatments consisted of $13 \%$ sunlight (low irradiance from shade cloth) and 52\% sunlight (high irradiance from natural greenhouse conditions). Based on measurements on photon flux densities $\left(\mu \mathrm{mol} \cdot \mathrm{m}^{-2} \cdot \mathrm{s}^{-1}\right)$ with a quantum radiometer (model LI-170, LI-COR, Lincoln, Nebr.), the fibergrass roof provided $\approx 52 \%$ sunlight transmission. The low irradiance treatment was achieved by mounting a saran shade cloth with $73 \%$ light filtering property on a PVC frame and supported $50 \mathrm{~cm}$ above the turf containers. The shade cloth reduces light intensity but does not affect quality (Allard et. al., 1991). The shade cloth was draped on all sides to prevent the effect of incline light. The shade cloth plus fibergrass roof allowed only $13 \%$ sunlight transmission.

Trinexapac-ethyl was applied to 24 pots at $0.048 \mathrm{~kg} \cdot \mathrm{ha}^{-1}$ a.i. $2 \mathrm{~d}$ after the application of irradiance treatments with a $\mathrm{CO}_{2}$-pressurized sprayer that delivered $550 \mathrm{~L} \cdot \mathrm{ha}^{-1}$ at a pressure of $1.5 \mathrm{~kg} \cdot \mathrm{cm}^{-2}$. Trinexapac-ethyl was repeatedly applied at the same rate at monthly intervals. The remaining 24 pots that subjected to no TE application were considered the controls.

During week 1 to week 6 after the initiation of shade treatment, data on canopy height and clipping yield were determined weekly. Canopy height was measured prior to each clipping event. Aruler was set on end on the soil surface, and a thin 10-cm diameter cardboard disc with a hole in its center was dropped freely over the ruler onto the turf canopy. Canopy height was read as the distance between the soil surface and the disk. Clippings were collected at each clipping event, and dried at $70{ }^{\circ} \mathrm{C}$ for $48 \mathrm{~h}$ for dry weight determination.

Gibberellic acid measurement. About 6 weeks after the initial shading treatments and 2 weeks after the second TE treatment, leaf tissues were sampled to determine $\mathrm{GA}_{1}$ and $\mathrm{GA}_{20}$ content. Samples were collected from each container, immediately freeze-dried (Genesis 25LL Lyophilizer, Virtis, Gardiner, N.Y.), and subsequently stored in air-tight bottles at $-20{ }^{\circ} \mathrm{C}$ until homogenization in $250 \mathrm{~mL}$ of cold $80 \%$ methanol. During homogenization, 
deuterium-labeled $(17,17-2 \mathrm{H} 2) \mathrm{GA}_{1}$ and $(17,17-2 \mathrm{H} 2) \mathrm{GA}_{20}$ were added to the extracts as internal standards. Deuterated GAs were obtained from Prof. Mander, Research School of Chemistry, Australian National Univ., Canberra, Australia. After overnight extraction, the filtered extracts were partitioned at least three times against hexane and diethyl ether, and further purified by column chromatography with charcoal : Celite, silicic acid : Celite, and QEAE-Sephadex-25. Detailed procedures used on GA purification were described by Talon and Zeevaart (1990) and Zeevaart (1971).

The extracted and purified GAs were methylated with ethereal diazomethane and then trimethylsilylated. Samples were analyzed by a gas chromatograph-mass spectrometer (GC-MS) (SATURN 2000, Varian Associates, Calif.). After injection, the oven temperature was maintained at $80^{\circ} \mathrm{C}$ for $0.5 \mathrm{~min}$, and then increased to $200^{\circ} \mathrm{C}$ at $25^{\circ} \mathrm{C} / \mathrm{min}$, followed by a further increase to $300{ }^{\circ} \mathrm{C}$ at $5^{\circ} \mathrm{C} / \mathrm{min}$. The $\mathrm{He}$ inlet pressure was $100 \mathrm{kPa}$ and the injector, interface, and source temperatures were $250^{\circ} \mathrm{C}, 250^{\circ} \mathrm{C}$, and $190^{\circ} \mathrm{C}$, respectively. The prominent ion pairs of 506/508 and 418/420 (endogenous/di-deuterated) of $\mathrm{GA}_{1}$ and $\mathrm{GA}_{20}$ were monitored. Since the amounts of deuterium-labeled $\left(17,17-2 \mathrm{H}_{2}\right) \mathrm{GA}_{1}$ and $\left(17,17-2 \mathrm{H}_{2}\right)$ $\mathrm{GA}_{20}$ (internal standards) added to the extracts were known, endogenous $\mathrm{GA}_{1}$ and $\mathrm{GA}_{20}$ content was calculated from the peak area ratios of $\mathrm{m} / \mathrm{z}$ (mass to charge signals) 506/508 and 418/420, respectively (Watson, 1997).

Data analysis. There were variations in canopy height and clipping yield among different measurement dates. However, the rank of treatments for clipping yield and canopy height was largely orderly, therefore, the averages over six consecutive weekly measurements for clipping yield and canopy height were subjected to analysis of variance (ANOVA) test. The ANOVA was conducted for data on canopy height (average over six measurements), clipping yield (average over six measurements), $\mathrm{GA}_{1}$ and $\mathrm{GA}_{20}$ content (week 6 sampling only) using the GLM procedure (Table 1). Means were separated using Fisher's protected least significant difference (LSD) (SAS Institute, 1989). Correlation analysis was performed to determine the relationship between the canopy height and GA content at 6 weeks after shading treatment.

\section{Results and Discussion}

Canopy height and clipping yield. Shoot elongation, expressed as canopy height, was different among the three cultivars. At high irradiance, 'Kenblue' and 'Livingston' exhibited $23 \%$ and $19 \%$ higher shoot elongation than 'NuGlade', respectively, over six measurement dates (Fig. 1). Reducing light intensity from $52 \%$ to $13 \%$ sunlight promoted control (pots that were not subjected to TE treatments) shoot elongation by $33 \%$ for 'Kenblue', $32 \%$ for 'Livingston', and 26\% for 'NuGlade'. Application of TE reduced shoot elongation of all KBG cultivars at both high and low irradiance conditions.
Table 1. Analysis of variances with mean square and treatment significance of canopy height, clipping yield, $\mathrm{GA}_{1}$, and $\mathrm{GA}_{20}$ content.

\begin{tabular}{|c|c|c|c|c|}
\hline Source & $\begin{array}{c}\text { Canopy height } \\
(\mathrm{cm})\end{array}$ & $\begin{array}{l}\text { Clipping yield } \\
\text { (g/pot) }\end{array}$ & $\begin{array}{c}\mathrm{GA}_{1} \\
(\mathrm{ng} / \mathrm{g})\end{array}$ & $\begin{array}{c}\mathrm{GA}_{20} \\
(\mathrm{ng} / \mathrm{g})\end{array}$ \\
\hline Shade (S) & $50.5^{* * * * *}$ & $14.6^{* * * * *}$ & $121.4^{* * * * *}$ & $143^{* * * * *}$ \\
\hline TE & $25.2^{* * * * *}$ & $8.2^{* * * * *}$ & $313.0^{* * * * *}$ & $1677^{* * * * *}$ \\
\hline $\mathrm{S} \times \mathrm{TE}$ & $0.76^{\mathrm{Ns}}$ & $1.9^{* * *}$ & 7.4 & 10.7 \\
\hline Cultivar (C) & $11.4^{* * * *}$ & $0.15^{* *}$ & $10.0^{* *}$ & $5.6^{\mathrm{Ns}}$ \\
\hline $\mathrm{S} \times \mathrm{C}$ & $2.9 * *$ & $0.18^{* *}$ & $0.5^{\text {ns }}$ & $1.7^{\mathrm{Ns}}$ \\
\hline $\mathrm{TE} \times \mathrm{C}$ & $1.0^{\mathrm{Ns}}$ & $0.14^{*}$ & $1.4^{\mathrm{NS}}$ & $2.4^{\mathrm{NS}}$ \\
\hline $\mathrm{S} \times \mathrm{TE} \times \mathrm{C}$ & $0.3^{\mathrm{ss}}$ & $0.1^{\mathrm{Ns}}$ & $0.5^{\mathrm{ss}}$ & $3.5^{\mathrm{Ns}}$ \\
\hline
\end{tabular}

respectively.
Low irradiance

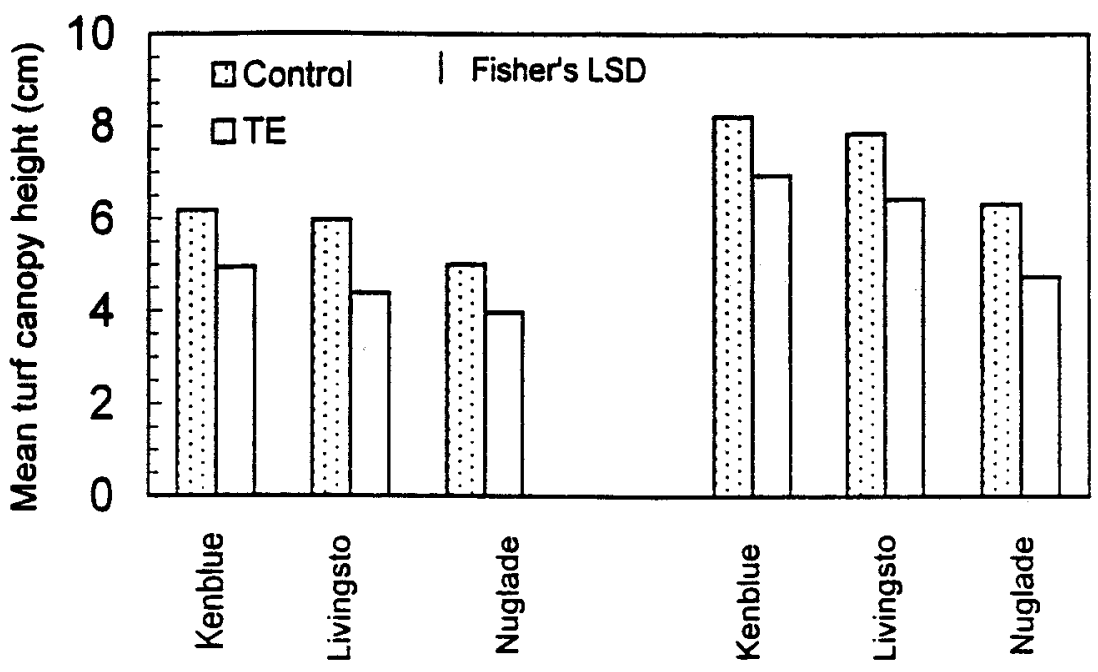

Fig. 1. Effects of irradiance and trinexapac-ethyl treatment on mean canopy height of 'Kenblue', 'Livingston', and 'NuGlade' Kentucky bluegrass. Canopy height was measured weekly prior to each clipping event and data were averaged 1 to 6 weeks after shading treatment. Vertical line represents Fisher's protected LSD.
High irradiance Low irradiance

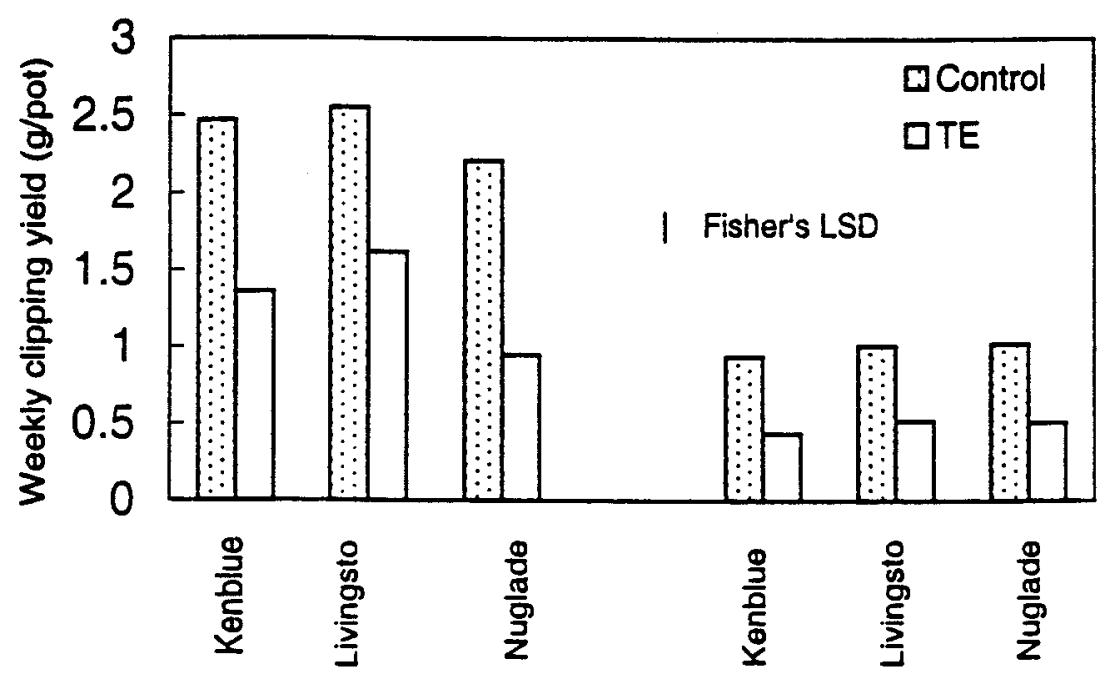

Fig. 2. Mean weekly clipping yield of 'Kenblue', 'Livingston', and 'NuGlade' Kentucky bluegrass as influenced by irradiance and trinexapac-ethyl treatment. Clipping yield was measured weekly and data were averaged 1 to 6 weeks after shading treatment. Vertical line represents Fisher's protected LSD. 
In contrast to height, clipping yield decreased $59 \%$ across all three cultivars as the level of irradiance decreased from 52\% to $13 \%$ sunlight (Fig. 2). At high irradiance, 'Kenblue' and 'Livingston' control plants produced higher clipping yield than 'NuGlade'. At low irradiance, however, cultivars did not differ in their clipping yields. This result suggested that 'NuGlade' had less reduction in clipping yield than 'Kenblue' and 'Livingston' as light intensity was reduced. Application of TE reduced clipping yield at both high and low irradiance through out the study (Fig. 2).

$G A$ content. The shoot content of GA1, the biological active GA, was different between the two light intensities and among the three cultivars (Fig. 3 ).

At high irradiance, $\mathrm{GA}_{1}$ content ranged from 8 to $10 \mathrm{ng} / \mathrm{g}$. Reducing light intensity from $52 \%$ to $12 \%$ sunlight increased GA by $47 \%$ in all control plants. This increase in GA was moderate when compared with Brassica (Brassicanapus L.) and pea (Pisum sativum L.) (Gawronska et al., 1995; Potter et al., 1999). In Brassica, $\mathrm{GA}_{1}$ concentration increased 7 - to 25 -fold and $\mathrm{GA}_{3}$ concentration increased 8 - to 25 -fold when light intensity decreased from 500 to $25 \mu \mathrm{mol} \cdot \mathrm{m}^{-2} \cdot \mathrm{s}^{-1}$ (Potter et al., 1999). The increase was 2- to 3 -fold when light intensity decreased from 500 to $150 \mu \mathrm{mol} \cdot \mathrm{m}^{-2} \cdot \mathrm{s}^{-1}$. In pea, $\mathrm{GA}_{1}$ level increased 2-fold as light level decreased from 386 to $193 \mu \mathrm{mol} \cdot \mathrm{m}^{-2} \cdot \mathrm{s}^{-1}$ (Gawronska et al., 1995). The authors found that increased biosynthesis of GA partially contributed to excessive shoot growth of pea in response to low light intensity.

'NuGlade' exhibited $20 \%$ lower GA 1 content than 'Kenblue'. GA content in 'Livingston' was not different from either 'Kenblue' or 'NuGlade'. This result suggested that the dwarf characteristics of 'NuGlade' were, at least in part, associated with low $\mathrm{GA}_{1}$ content (Fig. 3).

Across cultivars, application of TE reduced GA content by $49 \%$ under $13 \%$ sunlight and by $47 \%$ for KBG grown under $52 \%$ sunlight, indicating that the efficiency of TE was similar between two irradiance levels in KBG. However, in zoysiagrass (Zoysia japonica Steud.), Qian et al. (1998) found that the effectiveness of TE in reducing vertical shoot growth generally increased with increasing shade level.

Correlation analysis revealed that shoot elongation was correlated with $\mathrm{GA}_{1}$ content with a correlation coefficient of 0.71 for the control and 0.53 for TE-treated plants (Fig.5), indicating $\mathrm{GA}_{1}$ played an important role in increasing the shoot elongation of turfgrass grown under low light conditions.

$G A_{20}$ content. There were no differences in $\mathrm{GA}_{20}$ content among control cultivar plants under either level of irradiance (Fig. 4). Pooled data of all cultivars indicated that a light reduction of $73 \%$ increased $\mathrm{GA}_{20}$ content by $30 \%$, although no differences were found when analyzed by individual cultivars. Gawronska et al. (1995) found that as light intensity decreased from 386 to $193 \mu \mathrm{mol} \cdot \mathrm{m}^{-2} \cdot \mathrm{s}^{-1}$, the level of $\mathrm{GA}_{20}$ increased 3.7 fold in pea plants. Likewise, Potter et al. (1999) reported a 4-fold increase
High irradiance

Low irradiance

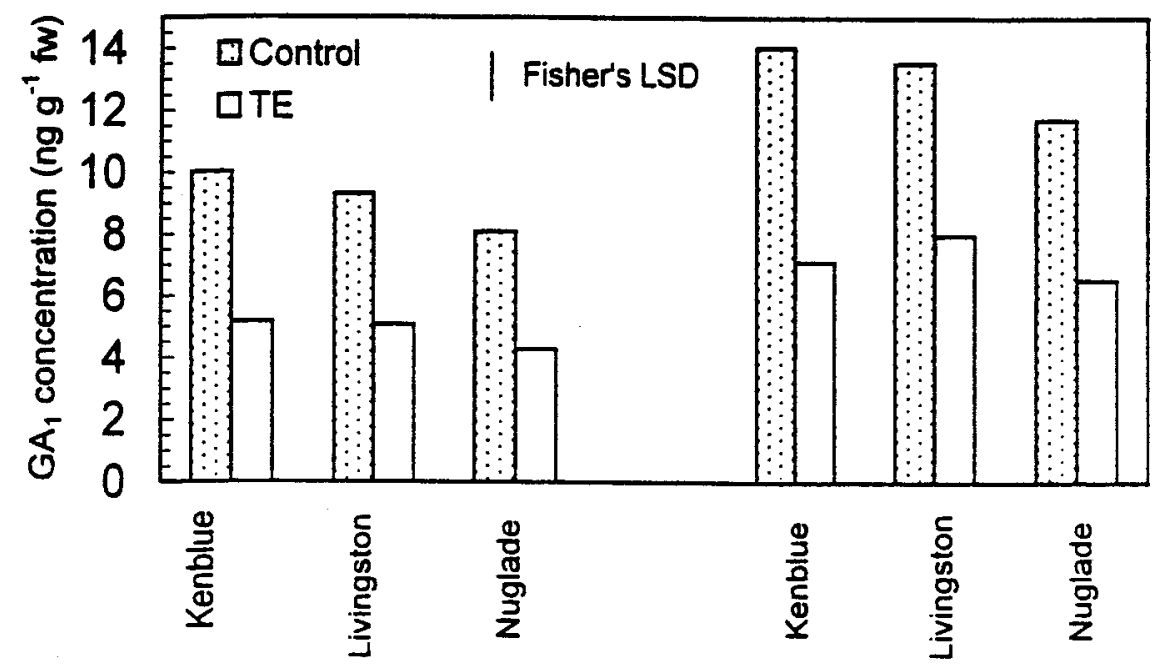

Fig. 3. GA content in shoots of 'Kenblue', 'Livingston', and 'NuGlade' Kentucky bluegrass as influenced by irradiance and trinexapac-ethyl treatment. Vertical line represents Fisher's protected LSD. of $\mathrm{GA}_{20}$ as light intensity decreased from 500 to $150 \mu \mathrm{mol} \cdot \mathrm{m}^{-2} \cdot \mathrm{s}^{-1}$ in Brassica.

Application of TE dramatically increased $\mathrm{GA}_{20}$ content for all cultivars at both irradiance levels (Fig. 4). The reduced GA and increased $\mathrm{GA}_{20}$ by TE treatment support a conclusion that TE inhibited $\mathrm{GA}_{1}$ biosynthesis by blocking the conversion of $\mathrm{GA}_{20}$ to $\mathrm{GA}_{1}$.

Shoot elongation was correlated with $\mathrm{GA}_{20}$ content with a correlation coefficient of 0.42 for the control and 0.54 for TE-treated plants (Fig. 5). However, correlation analysis of pooled data of both with and without TE treated plants resulted in no relationship between $\mathrm{GA}_{20}$ and canopy height. This is because $\mathrm{GA}_{20}$ itself does not promote shoot elongation, but its product $\left(\mathrm{GA}_{1}\right)$ does.
In summary, the results from this study indicated that both $\mathrm{GA}_{1}$ and $\mathrm{GA}_{20}$ increased under low irradiance in KBG. The concentration of $\mathrm{GA}_{1}$ played an important role in increasing the shoot elongation of turfgrass grown under low light conditions. Previous research with zoysiagrass suggested that turf quality negatively correlated with shoot vertical growth under dense shade conditions (Qian et al., 1998). Several implications may be drawn from these results with respect to selection and management of KBG under low light irradiance: 1$) \mathrm{KBG}$ cultivars that perform better under shade conditions should be those that minimize vertical growth under shade and divert energy to maintaining horizontal growth; 2) GA manipulation through using

\section{High irradiance}

\section{Low irradiance}

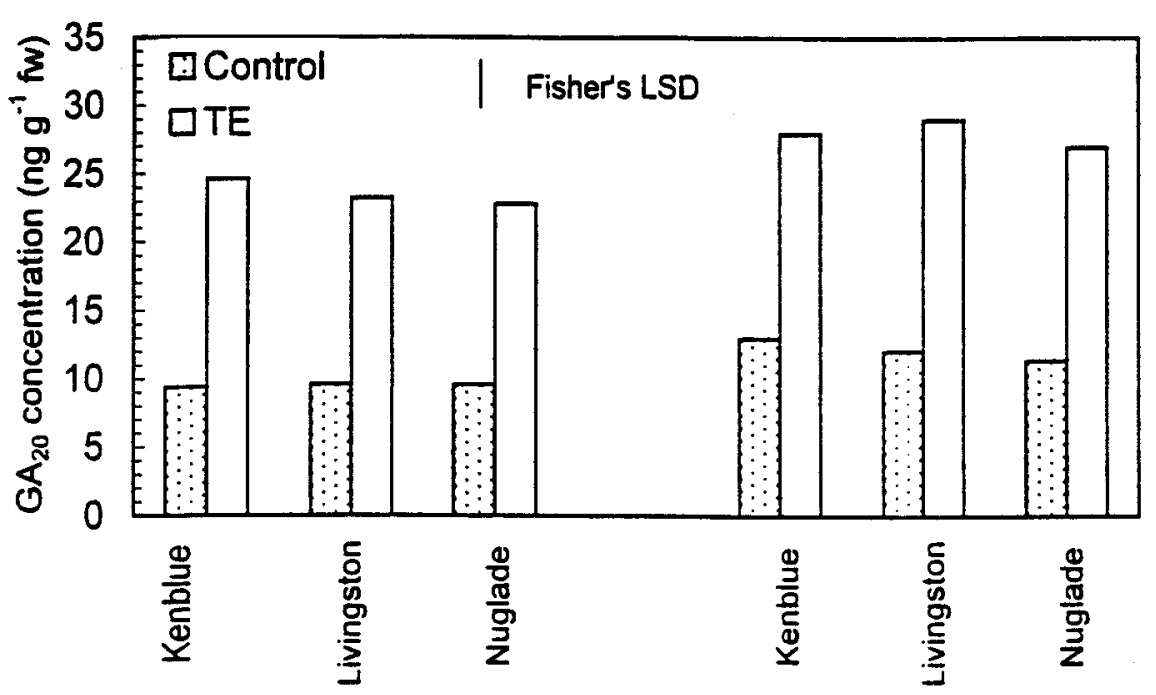

Fig. 4. GA ${ }_{20}$ content in shoots of 'Kenbue', 'Livingston', and 'NuGlade' Kentucky bluegrass as influenced by irradiance and trinexapac-ethyl treatment. Vertical line represents Fisher's protected LSD. 


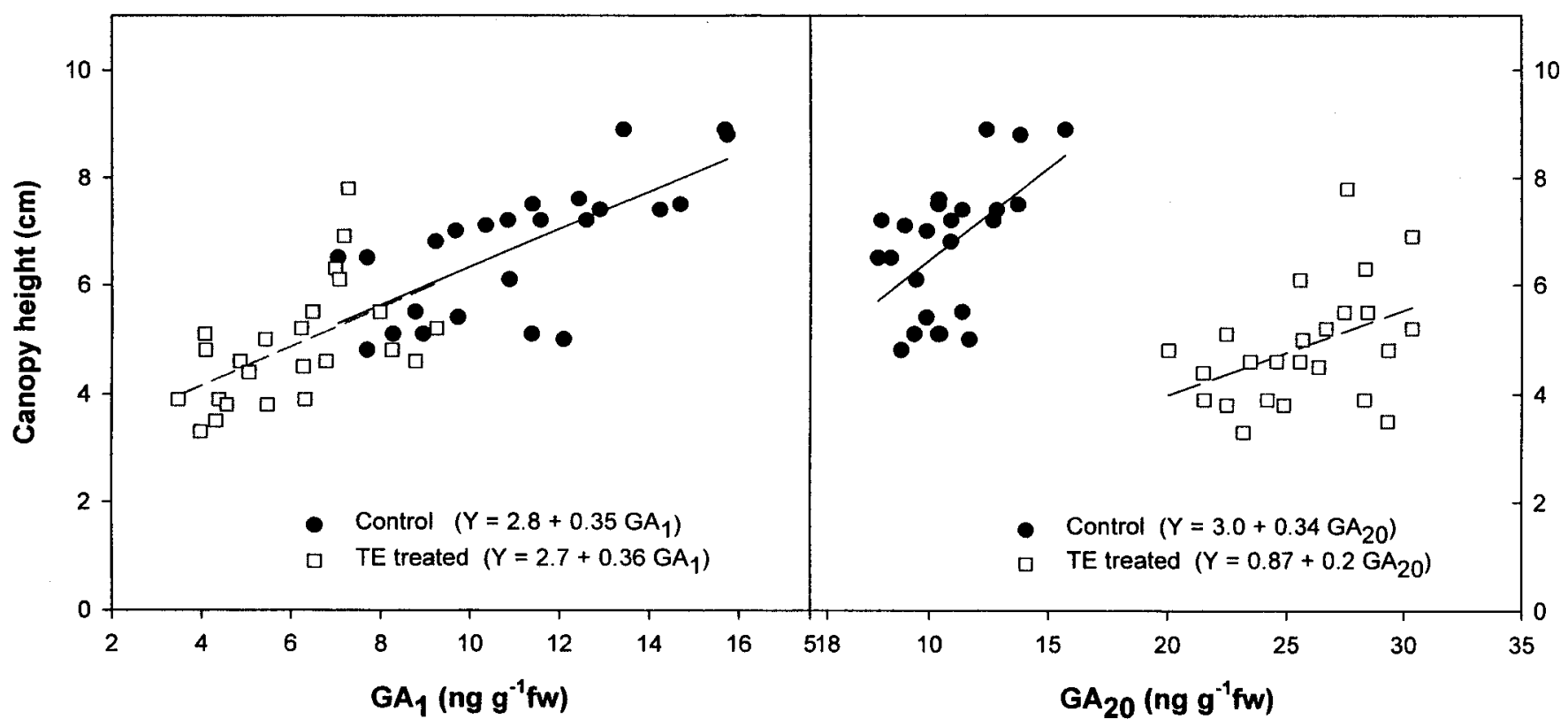

Fig. 5. Correlation of canopy height vs. (A) $\mathrm{GA}_{1}$ and (B) $\mathrm{GA}_{20}$ content.

anti-GA plant growth regulators may favorably affect turf stature, thereby increasing the shade tolerance of turf.

\section{Literature Cited}

Adams R, E. Kerber, K. Pfister, E.W. Weiler. 1992. Studies on the action of the new growth retardant CGA 163'935 (Cimectacarb). p. 818-827. In C.M. Karssen, L.C. van Loon and D. Vreugdenhil (eds.). Progress in plant growth regulation. Kluwer Academic Publishers, Dordrecht.

Allard, G., C.J. Nelson, and S.G. Pallardy. 1991. Shade effects on growth of tall fescue: I. Leaf anatomy and dry matter partitioning. Crop Sci. 31:163-167.

Beard, J.B. 1965. Factors in the adaptation of turfgrasses to shade. Agron. J. 57:457-459.

Ervin, E.H., C. Ok, B.F. Fresenburg, J.H. Dunn. 1999. Influence of trinexapac-ethyl on Meyer zoysiagrass in reduced field light environment. Agron. Abstr. 122.
Gawronska, H., and Y. Yang, K. Furukawa, R.E. Kendrick, N. Takahashi, and Y. Kamiya. 1995. Effects of low irradiance stress on gibberellin levels in pea seedings. Plant Cell Physiol. 36: 1361-1367.

Graebe, J.E. 1987. Gibberellin biosynthesis and control. Annu. Rev. Plant Physiol. 38: 419-465.

Heide, O.M., M.G. Bush, and L.T. Evans. 1985. Interaction of photoperiod and gibberellin on growth and photosynthesis of high latitude $\mathrm{Poa}$ pratensis. Physiol. Plant. 65:135-145.

Junttila, O., O.M. Heide, B. Lindgard, and A. Ernstsen. 1997. Gibberellins and photoperiodic control of leaf growth in Poa pratensis. Physiologia Plantarum 101:599-605.

Potter, T.I., S. B. Rood, and K.P. Zanewich. 1999. Light intensity, gibberellin content and resolution of shoot growth in Brassica. Planta 207: 505-511.

Qian, Y.L. and M.C. Engelke. 1999. Influence of trinexapac-ethyl on 'Diamond' Zoysiagrass in a shade environment. Crop Sci. 39:202-208.
Qian, Y.L., M.C. Engelke, M.J.V. Foster, and S. Reynolds. 1998. Trinexapac-ethyl restricts shoot growth and improves quality of 'Diamond' zoysiagrass under shade. HortScience 33:1096-1099.

Reid J.B. and J.J. Ross. 1991. Gibberellin mutants in Pisum and Lathyrus. p. 40-50. In Takahashi et el. (eds.), Gibberellins. Spinger Verlag, New York.

Stier, J.C. and J.N. Rogers III. 2001. Trinexapacethyl and iron effects on supina and Kentucky bluegrass under low irradiance. Crop Sci. 41: 457-465.

Talon M. and J.A.D. Zeeraart. 1990. Gibberellins and stem growth as related to photoperiod in $\mathrm{Si}$ lene armelia L. Plant Physiol 92:1094-1100.

Watson, J.T. 1997. Introduction to mass spectrometry. Lippincott-Raven Publishers, Philadelphia, N.Y.

Zeevaart J.A.D. 1971. Effects of photoperiod on growth rate and endogenous gibberellins in the long-day rosette plant spinach. Plant Physiol. 47:821-827. 